\title{
The Role of Empathy in Professional Quality of Life: a Study on Australian Police Officers Working in Sexual Assault and Child Abuse Investigation
}

\author{
Riana K. Losung ${ }^{1,2} \cdot$ Tara De Paoli $^{3} \cdot$ Mark Kebbell $^{1} \cdot$ Amanda Bond $^{2}$
}

Accepted: 2 July 2021 / Published online: 29 July 2021

(c) Crown 2021

\begin{abstract}
Police working in sexual assault and child abuse investigation may be at risk of secondary trauma effects and burnout, particularly if they do not have protective mechanisms in place. Empathy has shown to be vital in protecting against secondary trauma and burnout, as well as enhancing compassion satisfaction. The current cross-sectional study surveyed 216 Australian police participants working in sexual assault and child abuse investigation exploring the relationship between different facets of empathy and professional quality of life factors. All facets of empathy predicted compassion satisfaction and negatively predicted burnout. Aspects of cognitive empathy negatively predicted burnout and secondary traumatic stress, while aspects of emotional/physiological and cognitive empathy positively predicted compassion satisfaction. Novel gender differences were found, with males at higher risk of burnout; tenure significantly predicted burnout and secondary traumatic stress; and results supported that empathy is a vital mechanism for sustaining wellbeing, satisfaction, and efficacy in this work.
\end{abstract}

Keywords Police $\cdot$ Empathy $\cdot$ Trauma $\cdot$ Stress $\cdot$ Burnout $\cdot$ Fatigue

There is a large body of research which has found that police working in child abuse and sexual assault investigation are at higher risk for the development of poor mental health outcomes as a result of burnout and secondary trauma (Ahern et al. 2016; Parkes et al. 2018). For those who work in these crime themes, an increased psychological risk may result in impairment or their ability to function effectively (MacEachern et al. 2011; Parkes et al. 2018; Sprang et al. 2011). However, research into protective factors (Powell et al. 2014b; Tomyn et al. 2015) has found there are effective strategies which enable those in high-risk professions to mitigate these risks. Empathy has been proposed as a predictive mechanism in high-risk helping professions; however, the research is inconclusive as to whether it is a protective or risk factor (Beagley

Riana K. Losung

riana.losung@gmail.com

1 School of Applied Psychology, Griffith University, Mt Gravatt, Australia

2 Family Violence Command, Victoria Police, Melbourne, Australia

3 Psychology Services, Australian Federal Police, Melbourne, Australia et al. 2018; Wagaman et al. 2015). The current study provides a novel investigation into the relationship between empathy and professional quality of life factors: secondary traumatic stress (STS); burnout; and compassion satisfaction, within a police population investigating sexual assault and child abuse. The study aims to expand on Wagaman et al. (2015) research, which found that empathy constructs were positively related to compassion satisfaction, and negatively related to STS and burnout, by assessing their model in a police population.

\section{The Nature of Sexual Assault and Child Abuse Investigation}

The large number of vulnerable victims and resulting caseloads, grotesque themes, repetitive exposure to victims' trauma accounts, and long working hours associated with child abuse and sexual assault investigation are all contributing factors that compromise police wellbeing (Oxburgh et al. 2015; Wright et al. 2006). In addition, investigative teams involved in this work are required to view graphic images and videos of victims, including young children, being sexually exploited through assault and torture in efforts to identify these victims as well as locate perpetrators 
(Burns et al. 2008). Studies have found that individuals involved in this work may be at higher risk for experiencing secondary traumatic stress (STS) (Burns et al. 2008; Perez et al. 2010), and that consistent exposure has a cumulative effect (Marshall 2006).

Investigations involving child sexual exploitation, sexual abuse, and violence are generally protracted, taking many months or years before they come to trial, delaying the experience of practitioner fulfilment and ultimately reducing work satisfaction (Tomyn et al. 2015). The difficulty of the work is often further complicated by victim resistance, hostility, and non-compliance (Ahern et al. 2016). The potential for negative community perceptions due to high prevalence of poor court outcomes and sentences has also shown to influence adverse wellbeing outcomes for police investigating these crimes (Powell et al. 2014a; Wright et al. 2006). As such, the effects of poor wellbeing can have a significant propensity to impair work performance, which for police could result in compromised service and support to victims, ultimately impacting on the quality of work by investigators.

\section{Professional Quality of Life}

Professional quality of life can be conceptualised as a balance between compassion satisfaction and compassion fatigue. Compassion satisfaction is described as the pleasure one derives from helping others through the work one does, whether it be with people who need care or for the greater good of society (Stamm 2010). In contrast, compassion fatigue is described as the negative impact one experiences from helping individuals who are suffering as a result of their experience of a traumatic event (Pehlivan and Guner 2018). Compassion fatigue can be further broken down into the subscales of STS and burnout (Stamm 2010; Pehlivan and Guner 2018). STS is defined as the impact of one's secondary exposure (through reading or listening) to another's extremely stressful experiences (Stamm 2010). Burnout is associated with exhaustion, cynicism, and ineffectiveness in one's work (McCormack and Cotter 2013). Research into compassion fatigue (common in nursing, caregiving, and other frontline roles) has shown that it can develop in the context of those relationships where empathy occurs in the act of providing care for another (Figley 1995, 2002; Pehlivan and Guner 2018). Research has also shown moderate to high levels of compassion fatigue in those working with sexual offence perpetrators, including symptoms of intrusion, avoidance, and hyperarousal (Steed and Bicknell 2001). Furthermore, police working in child sexual exploitation investigation showed low compassion satisfaction and high STS and burnout (Brady 2017). Conversely, police working in general duties have reflected relatively low composite compassion fatigue scores (Agelidis 2020; Grant et al. 2019), which may be indicative of their shorter involvement with victims.

\section{Influencing Socio-demographic Factors}

\section{Tenure}

Evidence suggests that length of time working in these highrisk themes may be a predictor of compassion fatigue. A study on therapists working with sexual offenders found those newer to the field (less than 2 years) and those more experienced (beyond 4 years) had higher risk of compassion fatigue, burnout, intrusion, avoidance, and hyperarousal than those working for a moderate period ( 2 to 4 years) (Steed and Bicknell 2001). A later study (Way et al. 2004) supported these findings indicating early career therapists working in sexual assault counselling were at higher risk for secondary trauma than those later in their career even if they showed higher degrees of coping (both positive and negative strategies). Interestingly, a study on domestic violence workers found that longer tenure was associated with factors related to compassion satisfaction (Kulkarni et al. 2013). Similarly, Wagaman et al. (2015) study on social workers found that those longer in their profession had higher levels of compassion satisfaction and lower levels of burnout than those earlier in their careers. In contrast to these findings, Australian police working in sexual and violent offending teams were found to be at greater risk of STS the longer they worked in the crime theme, and their burnout risk increased as a function of years spent in their entire policing career (Gray and Grange 2019).

\section{Gender}

Gender differences have consistently been reported in studies involving police populations. For example, an American study found female police officers were at higher risk for burnout indicating perceptions of danger, unfairness, sexism, and low levels of comradery were some of their unique stressors (McCarty et al. 2007). This study was corroborated cross-culturally in an Italian police population determining that female officers, irrespective of rank, had higher levels of organisational stress and distress than their male counterparts (Maran et al. 2017). Furthermore, Tehrani's (2016) study on internet child abuse investigators supported these results, indicating females were at higher risk of posttraumatic stress disorder, burnout, and compassion fatigue. In line with these findings, an extensive literature review in first responders indicated female gender to be a significant risk factor for secondary traumatisation (Greinacher et al. 2019). Conversely, there was one recent study on Australian police working in sexual and violent offending teams 
which produced no gender differences for secondary trauma, burnout, and mental ill-health (Gray and Grange 2019).

\section{Geographical Location}

Literature has shown geographical location has a potential to influence professional quality of life factors. For example, a study by Sprang et al. (2007) found that regional and rural mental health trauma clinicians suffered higher levels of burnout than their metropolitan colleagues, however, did not vary in levels of compassion fatigue or compassion satisfaction.

\section{Protective Factors}

Increasing compassion satisfaction in those working in highrisk professions has found to protect against the development of STS and subsequently compassion fatigue (Sprang et al. 2007; Wagaman et al. 2015). A study on law enforcement investigators exposed to disturbing media images found that while there were correlations between exposure, cynicism, and STS, there were also high levels of professional efficacy indicating they felt that their work made a real difference (Perez et al. 2010). Despite some findings indicating general police populations have low levels of compassion satisfaction (Gray and Grange 2019), it is possible that for police working in victim-centric crime themes, compassion satisfaction could be high. This is especially plausible in circumstances where satisfaction is derived from the act of helping victims, listening to their story, connecting them with support, and working towards providing justice, thus mitigating risk for STS and burnout.

\section{The Role of Empathy}

Empathy has been described in its simplest form as "feeling and understanding the emotions and experiences of others" (Segal et al. 2017). More recently, empathy has been defined as a multi-faceted construct that includes emotional, physiological, and cognitive aspects (Lietz et al. 2011), and it is thought the full range of empathy occurs when all these facets are activated (Segal et al. 2017). Emotional and physiological aspects of empathy involve automatic and unconscious mirroring of another's actions (Wagaman et al. 2015). These aspects of empathy have also been found to have a neural basis with neuroimaging research implicating mirror neurons in the ability to empathise (Shamay-Tsoory 2011). Cognitive aspects of empathy involve perspective taking, distinguishing the self from others, and regulating one's emotions (Wagaman et al. 2015).
Many police officers drawn to working within sexual assault and child abuse investigation gain satisfaction from working with victims and a critical skill in this work is empathy (Maddox et al. 2011; Oxburgh and Ost 2011; Peterson and Silver 2017). Empathy has been studied in policing populations primarily in relation to its role in victim engagement and case outcomes (Dando and Oxburgh 2015; Oxburgh and Ost 2011). A study examining police attitudes towards sex offenders found lower overall empathy levels in police when compared to the general population; however, police in this study demonstrated better perspective-taking abilities (a cognitive aspect of empathy) (Johnson et al. 2007). This could indicate police officers have a better understanding than the general population of circumstances leading to sexual offending. Another explanation could be that police display higher levels of cognitive empathy as a protective mechanism, thus mitigating against emotional responses towards victims.

Gender differences have also been noted in the empathy literature. A study on police working in victim-centric themes found female officers had higher "trait empathic emotion", which is linked to both emotional and cognitive domains of empathy (Rose 1999). Segal et al. (2017) findings supported this, indicating females were more likely than males to exhibit high interpersonal empathy, which is also associated with both emotional and cognitive domains. Similarly, Dando and Oxburgh (2015) found female police officers working with sexual offenders displayed more empathic behaviour than their male counterparts.

It has been argued that some aspects of empathy are associated with psychological risk while other aspects are more protective (Yilmaz and Ustun 2018). Early studies such as one by Figley (1995) found those with higher empathy and capacity for feeling tend to be at higher risk of compassion stress. Later studies have corroborated this view including Nolte et al. (2017) who found empathy in midwives to be a risk factor in the development of secondary trauma and compassion fatigue. Similarly, Beagley et al. (2018) found that female police officers with high empathy and exposure to a traumatic event experienced post-traumatic stress and depressive symptoms; however, this was not seen in their male counterparts.

Conversely, other studies have shown low empathy to be associated with adverse mental health effects and in some studies empathy has shown protective benefit against the effects of burnout and secondary trauma. For example, Sifris et al. (2015) found in their study that low empathy was associated with psychological distress. Studies utilising modern multi-dimensional measures of empathy have found that certain factors of empathy result in higher effectiveness and worker satisfaction (Gerdes et al. 2012; Segal et al. 2017). In an attempt to clarify which aspects of empathy were associated with compassion satisfaction, and 
which were associated with STS and burnout, Wagaman et al. (2015) explored a multi-dimensional model of empathy and its relationship with professional quality of life factors. The four-factor empathy model measured social workers' levels of affective response (an emotional and physiological component), self-other awareness, perspective taking, and emotional regulation (all cognitive components respectively). In their study, they found self-other awareness was strongly related to compassion satisfaction and negatively related to STS suggesting it was a protective factor for this population. Emotional regulation was negatively related to burnout and STS indicating it also has protective benefits. Affective response was found to indirectly protect against STS and burnout through its strong positive correlation with compassion satisfaction. As a result of their findings, Wagaman et al. (2015) concluded that empathy was a key factor in maintaining wellbeing and career longevity in social workers.

\section{Gaps Within the Literature}

Literature exploring empathy and its relationship to professional quality of life factors has largely used therapeutic and clinical populations (Hatcher and Noakes 2010; Steed and Bicknell 2001; Wagaman et al. 2015). However, literature investigating these domains in police has been largely understated or qualitative in nature (Andersen and Papazoglou 2015). It is important to note the possibility of varying emotional implications when comparing the way in which those working with victims and offenders in a therapeutic capacity differs from those working with them in an investigative capacity.

Throughout the literature, researchers have used varying definitions of empathy that have not always considered its multi-dimensional nature (Yilmaz and Ustun 2018), resulting in inconsistent findings around its correlation with mental health factors (Beagley et al. 2018; Sifris et al. 2015). Research is also sorely needed in this field to enable better understanding of the factors that contribute to positive and negative mental health outcomes in police investigators working in these themes. In turn, this will inform best practice for investigators as well as quality services to victims.

\section{The Current Study}

The current study aims to address these gaps within the literature by utilising a multi-dimensional measure for empathy. Furthermore, this study will utilise an evidence-based model of measuring professional quality of life that provides an assessment of STS and burnout (the two subscales of compassion fatigue), and compassion satisfaction. To expand on Wagaman et al. (2015) findings, the current study will be conducted in an Australian population of police working in sexual assault and child abuse investigation.

\section{Hypothesis}

In line with Wagaman et al. (2015) and existing research outcomes on these constructs, it was hypothesised that higher levels of the cognitive empathy components would be negatively associated with burnout and STS, while higher levels of the emotional/physiological and cognitive empathy components would be associated with compassion satisfaction. Further, it is anticipated the socio-demographic factors of gender, tenure, and geographical location will show significant effects on the outcome variables.

\section{Method}

\section{Participants and Procedure}

Police officers from an Australian police organisation working within units investigating crimes relating to child abuse, sexual assault, and family violence were invited via email to participate in an online survey via Qualtrics online software. Data were collected August and September of 2019. A total of 216 participant responses were used in the study following exclusion of those with incomplete responses.

The sample consisted of $N=216$ police detectives ( $n=102$ males, $n=109$ females, $n=5$ prefer not to say). Participants ranged in age between 25 and 64 years, with a majority aged between 30 and 54 years $(84.2 \%, n=182)$. Most of the sample identified their rank as Senior Constable/Leading Senior Constable $(74.54 \%, n=161)$ with others identifying as Senior Sergeant $(6.50 \%, n=14)$, Sergeant $(15.70 \%, n=34)$, Constable/First Constable $(0.50 \%, n=1)$, and $2.8 \%, n=6$ preferred not to say. The majority of participants reported working within the police force between 6 and 39 years $(96.30 \%, n=208)$, with a minority between 1 and 5 years $(3.2 \%, n=7)$ and $0.5 \%, n=1$ with more than 40 years tenure in the police force. Experience working in the theme of child abuse, sexual offending, and/or family violence ranged from less than 1 year to $>20$ years with a majority of police investigators with 1 to 5 years' experience ( $45.83 \%, n=99)$, followed by those with 6 to 12 months ( $20.37 \%, n=44), 6$ to 10 years $(16.67 \%, n=36)$, and 11 to 19 years $(11.11 \%, n=24)$. Participants reported working in metropolitan locations $(60.19 \%, n=130)$ and regional/rural $(37.96 \%, n=82)$, while others preferred not to identify their location $(1.85 \%, n=4)$. 


\section{Measures}

Socio-demographic information on participant gender, age group, rank, time working in police force, time working in sexual assault, child abuse and/or family violence crime theme, and geographical location were collected.

Empathy was measured using the Empathy Assessment Index (EAI), a 22-item self-report instrument, measuring five factors of empathy. The first two, affective response and affective mentalising, were defined as the emotional/ physiological components. The other three, self-other awareness, perspective taking, and emotional regulation, were all defined as cognitive components (Gerdes et al. 2012; Lietz et al. 2011; Segal et al. 2017). It should be noted that the version of the EAI used in this study was the most recent version and included the fifth factor of "affective mentalising", not included in Wagaman et al. (2015) study. Items were measured on a 6-point Likert scale $(1=$ never to $6=$ always $)$.

The Professional Quality of Life (ProQOL; Stamm 2010) Scale is a 30 -item self-report questionnaire used to measure the constructs of compassion satisfaction, STS, and burnout. Each of the three subscales had 10 questions with responses measured on a 5 -point Likert scale $(1=$ never to $5=$ very often). The scales of STS and burnout make up the latent construct compassion fatigue. The ProQOL measure has been deemed reliable and valid in measuring the constructs of both compassion satisfaction and compassion fatigue (Stamm 2010).

\section{Analytic Strategy}

Descriptive statistics, correlations, and multiple regression analyses were conducted with SPSS (version 23). To test whether there were any significant effects on the socio-demographic variables, an ANOVA and independent samples $t$-tests were run against the outcome variables of the ProQOL and empathy respectively. To test hypotheses relating to the associated relationships between empathy and professional quality of life factors, a correlations table including all factors was constructed followed by three multiple regressions: (1) with the dependent variable burnout; (2) with the dependent variable STS; and (3) with the dependent variable compassion satisfaction. In line with the analyses conducted by Wagaman et al. (2015), each model included as independent variables the five factors of empathy from the EAI, affective response, affective mentalising, self-other awareness, perspective taking, and emotional regulation, and controlled for the socio-demographic factors of gender, time working in the crime theme, and geographical location. The independent and outcome variables are summarised in Table 1.

\section{Results}

\section{Socio-demographics}

In line with the hypotheses, socio-demographic factors showed partial significance against the outcome variables.

\section{Tenure}

Tenure was measured as time working in the themes of sexual assault, child abuse, and/or family violence investigation. A one-way ANOVA was conducted for each of the three ProQOL variables (burnout, STS, and compassion satisfaction). Significant differences were found between tenure groups for STS $(F(4,208)=2.80, p<0.05)$ and burnout $(F(4,205)=3.95, p<0.01)$, but not for compassion satisfaction $(F(4,202)=1.98$, n.s. $)$. Post hoc Bonferroni comparisons indicated those with $<1$ year working in the themes had lower risk for STS than those working in the themes from $1-5$ years. Furthermore, those with $<1$ year working in the themes had a lower risk of burnout than those from 1-5 years
Table 1 Descriptive statistics for variables of interest by gender

\begin{tabular}{|c|c|c|c|c|c|c|c|c|}
\hline \multirow[t]{2}{*}{ Variable } & \multicolumn{3}{|l|}{ Total } & \multicolumn{2}{|l|}{ Males } & \multicolumn{2}{|c|}{ Females } & \multirow[b]{2}{*}{$p$} \\
\hline & Range & M & SD & M & SD & M & SD & \\
\hline Compassion satisfaction (raw score) & $14-50$ & 34.90 & 7.29 & 34.01 & 8.04 & 35.90 & 6.47 & \\
\hline Burnout (raw score) & $12-43$ & 26.26 & 6.31 & 27.70 & 6.83 & 24.79 & 5.51 & $<.01$ \\
\hline Secondary traumatic stress (raw score) & $10-43$ & 19.78 & 6.34 & 20.54 & 6.98 & 18.98 & 5.69 & \\
\hline Affective response & $1-5.8$ & 4.22 & 0.82 & 3.97 & 0.73 & 4.44 & 0.84 & $<.001$ \\
\hline Affective mentalising & $1-6$ & 4.30 & 0.83 & 4.13 & 0.78 & 4.47 & 0.83 & $<.01$ \\
\hline Self-other awareness & $1-6$ & 4.27 & 0.80 & 4.07 & 0.77 & 4.43 & 0.79 & $<.01$ \\
\hline Perspective taking & $1-6$ & 4.36 & 0.73 & 4.24 & 0.69 & 4.46 & 0.75 & $<.05$ \\
\hline Emotional regulation & $1.75-6$ & 4.20 & 0.78 & 4.14 & 0.85 & 4.26 & 0.71 & \\
\hline
\end{tabular}

Raw cut-off scores for compassion satisfaction, burnout, and secondary traumatic stress: low scores $<22$, high scores $>42$. The EAI does not utilise norms or cut-off scores, rather it is used as an overall gauge to identify the stronger and weaker aspects of empathic abilities (Segal et al. 2017) 
and those from 6-10 years. Investigators working in the crime themes beyond 10 years did not produce any significant differences from those with less time working in the crime themes.

\section{Gender}

An independent samples $t$-test was conducted on gender with the five empathy constructs and with the ProQOL outcome variables ( $t$-tests were used in preference to a MANOVA for the purpose of exploring each component). Table 1 shows that although both genders had high average empathy scores, females indicated significantly higher empathy scores across four out of the five factors: affective response $(t(209)=-4.18, p<0.001)$, affective mentalising $(t(211)=-2.83, p<0.01)$, self-other awareness $(t(208)=-3.39, p=0.001)$, and perspective taking $(t(207)=-2.16, p<0.05)$ than males. There was no significant difference between genders for emotional regulation $(t(210)=-1.19, n . s$.$) . Table 1$ shows that although both gender groups indicated moderate average results for burnout, males showed significantly higher risk for burnout than females $(t(188)=3.35, p<0.001)$. There were no significant gender differences for STS $(t(208)=1.78, n . s$. $)$ or compassion satisfaction $(t(184)=-1.84, n . s$.$) . Overall, for compas-$ sion satisfaction, $n=29$ participants scored in the high range, and $n=9$ scored in the low range. For burnout, $n=1$ scored in the high range, and $n=52$ scored in the low range. Finally, STS showed $n=1$ participant scored in the high range and a majority of participants scored in the low range $(n=138)$.

\section{Geographic Location}

Independent samples $t$-tests indicated no significant differences between metropolitan-based police investigators and their rural/regional counterparts on burnout $(t(205)=0.40$, n.s. $)$ or $(\operatorname{STS} t(209)=-1.38$, n.s. $)$.

\section{Correlating Variables}

Bivariate correlations were conducted between the sociodemographic factors, professional quality of life factors, and empathy factors. In line with the hypotheses, significant correlations between a majority of variables were found and results are displayed in Table 2. Burnout was significantly correlated with gender $(r=-0.14, p<0.05)$ and tenure $(r=-0.15, p<0.05)$, and gender was correlated with affective response $(r=-0.20, p<0.01)$ and self-other awareness $(r=-0.21, p<0.01)$. With the exception of a non-significant association between affective mentalising and STS, all empathy factors were negatively associated with STS and burnout, and positively related to compassion satisfaction. Of all the empathy factors, emotional regulation had the highest correlations with STS $(r=-0.52$, $p<0.01)$, burnout $(r=-0.60, p<0.01)$, and compassion satisfaction $(r=0.52, p<0.01)$.

A strong inverse relationship was found between compassion satisfaction and burnout $(r=-0.75, p<0.01)$, and a strong positive relationship between burnout and STS $(r=0.61, p<0.01)$.

\section{Hierarchical Regression}

Hierarchical regression analyses were conducted to determine which predictors contributed the most variance to the outcome variables, with the model results summarised in Table 3. Hypotheses were supported showing higher levels of the cognitive empathy components negatively associating with burnout and STS, and higher levels of the emotional/ physiological and cognitive empathy components positively associating with compassion satisfaction. In the first

Table 2 Pearson's correlations of independent and outcome variables

\begin{tabular}{|c|c|c|c|c|c|c|c|c|c|c|c|}
\hline & 1 & 2 & 3 & 4 & 5 & 6 & 7 & 8 & 9 & 10 & 11 \\
\hline 1.Gender & & .05 & .03 & .06 & $-.14^{*}$ & -.02 & $.20^{* *}$ & .14 & $.21^{* *}$ & .12 & .03 \\
\hline 2.Location & & & -.10 & -.12 & .06 & .11 & -.09 & -.05 & -.12 & -.06 & -.02 \\
\hline 3.Tenure & & & & .05 & $.15^{*}$ & .09 & .12 & .07 & -.02 & .06 & -.04 \\
\hline 4.Compassion satisfaction & & & & & $-.75^{* *}$ & $-.39^{* *}$ & $.42^{* *}$ & $.34^{* *}$ & $.54^{* *}$ & $.48^{* *}$ & $.52^{* *}$ \\
\hline 5.Burnout & & & & & & $.61^{* *}$ & $-.26^{* *}$ & $-.22^{* *}$ & $-.49^{* *}$ & $-.34^{* *}$ & $-.60^{* *}$ \\
\hline 6.Secondary traumatic stress & & & & & & & $-.15^{*}$ & -.12 & $-.39^{* *}$ & $-.23^{* *}$ & $-.52^{* *}$ \\
\hline 7.Affective response & & & & & & & & $.62^{* *}$ & $.59^{* *}$ & $.66^{* *}$ & $.30^{* *}$ \\
\hline 8.Affective mentalising & & & & & & & & & $.62^{* *}$ & $.78^{* *}$ & $.27^{* *}$ \\
\hline 9.Self-other awareness & & & & & & & & & & $.75^{* *}$ & $.50^{* *}$ \\
\hline 10.Perspective taking & & & & & & & & & & & $.43^{* *}$ \\
\hline 11.Emotional regulation & & & & & & & & & & & \\
\hline
\end{tabular}

Note. ${ }^{*} p<.05 ;{ }^{* *} p<.01$ 
Table 3 Hierarchical regression analyses predicting participant burnout, secondary traumatic stress, and compassion satisfaction

\begin{tabular}{lccc}
\hline & Model 1: Burnout & $\begin{array}{l}\text { Model 2: Secondary traumatic } \\
\text { stress } \\
B \text { (beta) }\end{array}$ & $\begin{array}{l}\text { Model 3: } \\
\text { Compassion } \\
\text { satisfaction } \\
B \text { (beta) }\end{array}$ \\
\hline Intercept & 47.60 & 34.95 & 5.78 \\
Gender & $-0.81(-.09)$ & $0.16(.02)$ & $-0.39(-.04)$ \\
Tenure & $0.45(.09)$ & $0.25(.06)$ & $0.19(.04)$ \\
Location & $0.06(.01)$ & $0.86(.07)$ & $-0.71(-.05)$ \\
Affective response & $0.05(.03)$ & $0.13(.08)$ & $0.28^{*}(.16)$ \\
Affective mentalising & $0.18(.10)$ & $0.17(.09)$ & $-0.19(-.09)$ \\
Self-other awareness & $-0.60^{*}(-.30)$ & $-0.67 *(-.34)$ & $0.63 *(.28)$ \\
Perspective taking & $-0.03(-.02)$ & $0.11(.06)$ & $0.18(.09)$ \\
Emotional regulation & $-0.90^{* *}(-.44)$ & $-0.83^{* *}(-0.41)$ & $0.75^{* *}(.32)$ \\
Adjusted $R^{2}$ & $0.36^{* *}$ & $.29^{* *}$ & $.38^{* *}$ \\
$F$ & $15.83(8,191)$ & $11.51(8,196)$ & $15.67(8,189)$ \\
\hline
\end{tabular}

Note. $* p<.05 ; * * p<.01$ model, with burnout as the outcome variable, the first step of the regression showed gender and tenure had significant unique effects accounting for $4 \%$ of the variance $\left(R^{2}=0.04\right.$, adjusted $\left.R^{2}=0.04\right)$ in the model $(F(3,196)=3.02, p<0.05)$. In the second step, $36 \%$ of the variance $\left(R^{2}=0.40\right.$, adjusted $\left.R^{2}=0.36\right)$ was accounted for by the independent variables listed earlier $(F(8,191)=15.83, p<0.001)$ with self-other awareness $(\beta=-0.30, p<0.05)$, and emotional regulation $(\beta=-0.44, p<0.01)$ adding significant contribution to the model and the main effects of gender and tenure became non-significant. In the second model with STS as the outcome variable, the unique effect of gender, tenure, and location were not significant $\left(R^{2}=0.03\right.$, adjusted $\left.R^{2}=0.03\right)$ $(F(3,201)=1.88$, n.s. $)$. In step two, $29 \%$ of the variance $\left(R^{2}=0.32\right.$, adjusted $\left.R^{2}=0.29\right)$ was explained by the model $(F(8,196)=11.51, p<0.001)$ with self-other awareness $(\beta=-0.34, p<0.05)$ and emotional regulation $(\beta=-0.41$, $p<0.01)$ as significant predictors. In the third model, with compassion satisfaction as the outcome variable, the unique effect of gender, tenure, and location were not significant $\left(R^{2}=0.02\right.$, adjusted $\left.R^{2}=0.02\right)(F(3,194)=1.23$, n.s. $)$. In step two, $38 \%$ of the variance $\left(R^{2}=0.40\right.$, adjusted $\left.R^{2}=0.38\right)$ was explained by the model $(F(8,189)=15.67, p<0.001)$ with affective response $(\beta=0.16, p<0.05)$, self-other awareness $(\beta=0.28, p<0.05)$, and emotional regulation $(\beta=0.32$, $p<0.05)$ as significant predictors of the model.

The findings of this study indicate a significant relationship between empathy and professional quality of life factors for police investigators working in sexual assault and child abuse investigation. Self-other awareness and emotional regulation (both cognitive components of empathy) appear to be significant contributors to all three factors of professional quality of life. Affective response (an emotional and physiological component of empathy) was identified as a significant contributor to compassion satisfaction. These findings were significant beyond the socio-demographic effects of gender, tenure, and location.

\section{Discussion}

The current study represents the first quantitative analysis exploring the factors of empathy and their relationship with professional quality of life factors for police investigators working in sexual assault and child abuse investigation. The study findings support Wagaman et al.'s (2015) research suggesting empathy is protective against burnout and STS.

The primary focus of the study was on the relationship between empathy and professional quality of life. With the exception of a non-significant association between affective mentalising and STS, all empathy factors were negatively associated with STS and burnout, and positively associated with compassion satisfaction. The findings showed that the strongest correlation was the inverse relationship between compassion satisfaction and burnout, suggesting compassion satisfaction was a significant protective factor against the risk and development of burnout in police detectives working in sexual offending and child abuse investigation. Another strong relationship was between STS and burnout which has been corroborated in other populations such as mental health professionals working with trauma clients (Devilly et al. 2009). This suggests that STS and burnout may share similar characteristics where the risk for one may increase the risk for the other.

In line with the overarching hypotheses, empathy significantly influenced professional quality of life factors beyond the socio-demographic effects. Affective response, self-other awareness, and emotional regulation were found to predict compassion satisfaction. However, only the cognitive empathy factors of self-other awareness 
and emotional regulation negatively predicted STS and burnout. These results supported Wagaman et al. (2015) confirming compassion satisfaction requires emotional/ physiological as well as cognitive components of empathy, whereas only cognitive components of empathy protect against risk for burnout and STS. Thus, highlighting that empathy is a key protective factor against the development of burnout and STS, both directly and indirectly. These findings further support the model of empathy proposed by Segal et al. (2017) whereby a broad empathic response encompassing physiological/emotional as well as cognitive components serves to enable practitioner fulfilment, service user satisfaction, and mental health preservation for the practitioner.

In terms of socio-demographic factors, the findings partially supported the hypotheses with only tenure and gender producing significant effects. Results suggest that mid-career detectives (between 1 and 10 years) tend to be at higher risk of STS and/or burnout than early career detectives (less than 1 year). For STS, there was no significant increase in risk for those who had worked beyond 6 years in the crime theme. This could suggest that for new detectives in this field, a focus on learning processes and procedures could serve as a protective factor against STS, whereas repetitive exposure to the content and themes over time increases risk of STS. This finding supports the literature on the cumulative effect (Marshall 2006). However, another explanation could be for those beyond 6 years in the crime theme, established coping habits or desensitisation may protect against secondary trauma effects. Further, there may be a potential confound of age given those with shorter tenure tend to be younger, and those with longer tenure tend to be older, and literature supports the notion that people are generally happier in their earlier and later years than in their midlife (Laaksonen 2018). Burnout showed similar results with risk increasing significantly from those early in their career (less than 1 year) to those in their mid-career (between 1 and 10 years), suggesting the longer police work in these roles, the higher their risk for burnout. Those later in their career (beyond 10 years) did not show an increase in risk compared with those early or in their mid-career which may indicate similar reasoning to the STS results. In terms of compassion satisfaction, tenure showed no effect which conflicted with Wagaman et al. (2015) findings indicating that compassion satisfaction increased throughout the careers of social workers. A possible explanation could be that social work populations have opportunities for clinical supervision which are established and embedded into their practice, enabling positive reflection on their work and potentially increasing compassion satisfaction. Reflective practice has only recently been incorporated into some police jurisdictions (Christopher 2015), however, is only relatively new and is yet to determine any measurable effects.
Gender results also conflicted with previous research findings indicating male detectives had a significantly higher risk of burnout than female detectives. Further, female detectives scored higher than their male colleagues across four out of the five empathy domains (affective response, affective mentalising, self-other awareness, and perspective taking), indicating empathy may serve as a protective factor against the development of burnout. This was contrary to the majority of research conducted in general policing populations that attribute unique female stressors to gender differences in wellbeing (McCarty et al. 2007). The current study utilised special detectives in units where the gender balance is more evenly distributed, if not skewed with a higher number of females. These findings could suggest that females thrive in victim-centric policing where they can utilise their empathy skills and where there is a more balanced gender distribution.

Despite previous research suggesting that geographical location may be implicated in wellbeing outcomes, the current study found no significant differences for those in metropolitan areas versus regional and rural areas. Perhaps the regular rotation of police across regions coupled with standard operating procedures across jurisdictions means that work conditions are consistent regardless of location.

\section{Limitations}

Despite the novel findings of this study, there are a number of limitations to note. Firstly, the nature of the occupation for this population involves perceptions of stigma towards mental health, and so response bias may have influenced participant responses on the survey with the potential to skew results. Secondly, although this study controlled for some socio-demographic and environmental factors, there was no data collected on varying factors that could contribute to STS and burnout directly or indirectly such as perceived support from management or leadership style, workload, collegial support, or coping factors. Finally, the cross-sectional design of the study means cause and effect of the relationship between empathy and professional quality of life factors cannot be concluded definitively.

\section{Implications and Future Directions}

The current study represents the first investigation of professional quality of life factors in a policing population along with their relationship to empathy. The results provide significant insight into the empathic response which influences victim engagement, compassion satisfaction, and protection against burnout and secondary trauma. Further, the results and implications may generalise to other policing populations working in victim-centric crime themes and exposed to secondary trauma and burnout. Given empathy has shown to be an important skill in this work, and a protective 
factor, it may be valuable to seek out in potential recruits. Evidence suggests that empathy skills can be sought out during recruitment through the administering of emotional intelligence measures (Grubb et al. 2018) and aspects of empathy can also be cultivated (e.g. the cognitive components) through developing awareness and understanding of an individual's or group's life experiences, their privileges, as well as the social, political, and economic barriers that impact on them. This could be facilitated through specialised training on factors that increase the risk for generational child abuse or factors that influence development of sexual paraphilia in offenders. It is also important this type of training is continuous to ensure knowledge remains current and educative insights are preserved. Emotional empathy can be strengthened and regulated through emotional intelligence and psychological flexibility training (e.g. mindfulness and acceptance commitment therapy [ACT] techniques) and has been effectively demonstrated in various organisational populations (Decker et al. 2015; Lomas et al. 2017; Virgili 2015). Gradual exposure to traumatising material has also been regarded as helpful to police working in high-risk themes by enabling emotional and cognitive preparedness (Burns et al. 2008).

Given compassion satisfaction was the strongest predictor against the risk for burnout in this population, it is important to foster a narrative with police investigators about how they derive satisfaction in working with victims of sexual assault and child abuse. As police are generally stigmatised against talking about their emotions, interventions and a safe space for them to share these insights is vital to ensure these narratives are encouraged.

Lastly, the novel gender findings in this study suggest females are at lower risk for burnout than males and indicate females may cope slightly better in this environment. Furthermore, female detectives showed higher levels of empathy in general which indicate its protective value against poor mental health outcomes in these specialised policing units. These findings indicate that female officers may thrive in victim-centric policing where there is a better gender balance, where they can utilise their empathy skills, and where there may be potential for stronger feminist views than in other areas of policing. These findings further serve to advocate for interventions to support male officers working in these themes, while cultivating and encouraging empathy in an effort to promote their engagement and longevity in this field.

\section{Conclusion}

The current study investigated the role of empathy and professional quality of life in a high-risk policing population. The results indicated that empathy is vital for police investigators working in these themes to safeguard against the development of burnout and STS. Further, some components of empathy predict compassion satisfaction, protecting against burnout and STS thereby promoting longevity and retention in these roles. Empathy should be sought out in recruits for this work, then cultivated and preserved in an effort to encourage better outcomes for police, the victims with whom they engage, and policing organisations as a whole.

Availability of Data and Material Data subject to third party restrictions. The data that support the findings of this study are available from an anonymous policing organisation but restrictions apply to the availability of these data, which were used under license for the current study, and so are not publicly available. Data are however available from the authors upon reasonable request and with permission of the third party.

\section{Declarations}

Ethics Approval Ethics approval to conduct this study was obtained by both the Griffith University Research Ethics Committee (GUREC) and the Police Organisation's Human Research Ethics Committee on 11 June 2019

Consent to Participate The participants were recruited during the months of August and September 2019, and were invited by email to participate in an online, Qualtrics-based survey via Qualtrics online software (2014). An Explanatory Statement was provided and formed part of the agreement with participants in order to inform them of conditions of their participation. Participants were advised they could withdraw from the study at any stage without repercussion.

Consent for Publication Consent for publication was provided by the police organisation on the condition that confidentiality and anonymity of the origins of the sample used in this study were maintained.

Conflict of Interest The authors declare no competing interests.

\section{References}

Agelidis J (2020) A study of compassion fatigue among police officers. Journal of Applied Social Science Research and Practice 2:83113. https://firescholars.seu.edu/jassrp/vol2/iss1/6

Ahern A, Sadler LH, Lamb ME (2016) Wellbeing of professionals working with suspected victims of child sexual exploitation. Child Abuse Rev 26:130-140. https://doi.org/10.1002/car.2439

Andersen JP, Papazoglou K (2015) Compassion fatigue and compassion satisfaction among police officers: an understudied topic. International Journal of Emergency Mental Health and Human Resilience 17:661-663. https://doi.org/10.4172/1522-4821. 1000259

Beagley MC, Peterson ZD, Strasshofer DR, Galovski TE (2018) Sex differences in posttraumatic stress and depressive symptoms in police officers following exposure to violence in Ferguson: the moderating effect of empathy. Policing: An International Journal 41:623-635. https://doi.org/10.1108/PIJPSM-01-2017-0007

Brady P (2017) Crimes against caring: exploring the risk of secondary traumatic stress, burnout, and compassion satisfaction 
among child exploitation investigators. J Police Crim Psychol 32:305-318. https://doi.org/10.1007/s11896-016-9223-8

Burns CM, Morley J, Bradshaw R, Domene J (2008) The emotional impact on coping strategies employed by police teams investigating internet child exploitation. Traumatology 14:20-31. https://doi.org/10.1177/1534765608319082

Christopher S (2015) The police service can be a critical reflective practice...if it wants. Policing 9:326-339. https://doi.org/10.1093/ police/pav007

Dando CJ, Oxburgh GE (2015) Empathy in the field: towards a taxonomy of empathic communication in information gathering interviews with suspected sex offenders. Eur J Psychol Appl Leg Context 8:27-33. https://doi.org/10.1016/j.ejpal.2015.10. 001

Decker JT, Constantine Brown JL, Ong J, Stiney-Ziskind CA (2015) Mindfulness, compassion fatigue, and compassion satisfaction among social work interns. Social Work \& Christianity 42:2842. https://swc.nacsw.org/index.php/SWC

Devilly GJ, Wright R, Varker T (2009) Vicarious trauma, secondary traumatic stress, or simply burnout? Effect of trauma therapy on mental health professionals. The Royal Australian and New Zealand College of Psychiatrists 43:373-385. https://doi.org/ $10.1080 / 00048670902721079$

Figley C (1995) Compassion fatigue: coping with secondary traumatic stress disorder in those who treat the traumatized. Brunner-Routledge.

Figley CR (Ed.) (2002) Treating compassion fatigue. Brunner-Routledge. Gerdes KE, Geiger JM, Lietz CA, Wagaman MA, Segal EA (2012) Examination of known-groups validity for the Empathy Assessment Index (EAI): differences in EAI scores between social service providers and service recipients. J Soc Soc Work Res 3:94112. https://doi.org/10.5243/jsswr.2012.7

Grant HB, Lavery CF, Decarlo J ( 2019) An exploratory study of police officers: low compassion satisfaction and compassion fatigue. Frontline Psychology 9 https://doi.org/10.3389/fpsyg. 2018.02793

Gray C, Grange MR (2019) Individual characteristics, secondary trauma and burnout in police sexual and violent offending teams. The Police Journal: Theory, Practice and Principles 93 https://doi. org/10.1177/0032258X19847499

Greinacher A, Derezza-Greeven C, Herzog W, Nikendei C (2019) Secondary traumatization in first responders: a systematic review. Eur J Psychotraumatol 10 https://doi.org/10.1080/20008198.2018. 1562840

Grubb AR, Brown SJ, Hall P (2018) The emotionally intelligent officer? Exploring decision-making style and emotional intelligence in hostage and crisis negotiators and non-negotiator-trained police officers. J Police Crim Psychol 33:123. https://doi.org/10. 1007/s11896-017-9240-2

Hatcher RM, Noakes S (2010) Working with sex offenders: the impact on Australian treatment providers. Psychology Crime and Law 16:145-167. https://doi.org/10.1080/10683160802622030

Johnson H, Hughes JG, Ireland JL (2007) Attitudes towards sex offenders and the role of empathy, locus of control and training: a comparison between a probationer police and general public sample. The Police Journal 80:28-54. https://doi.org/10.1350/pojo.2007. 80.1.28

Kulkarni S, Bell H, Harman J, Herman-Smith RL (2013) Exploring individual and organizational factors contributing to compassion satisfaction, secondary traumatic stress, and burnout in domestic violence service providers. J Soc Soc Work Res 4:114-130. https://doi.org/10.5243/jsswr.2013.8

Laaksonen S (2018) A research note: happiness by age is more complex than U-shaped. J Happiness Stud 19:471-482. https:// link.springer.com/article/ https://doi.org/10.1007/s10902016-9830-1
Lietz CA, Gerdes KE, Fei S, Geiger JM, Wagaman MA, Segal EA (2011) The Empathy Assessment Index (EAI): a confirmatory factor analysis of a multidimensional model of empathy. J Soc Soc Work Res 2:104-124. https://doi.org/10.5243/jsswr.2011.6

Lomas T, Medina JC, Ivtzan I, Rupprecht S, Hart R, Eiroa-Orosa FJ (2017) The impact of mindfulness on wellbeing and performance in the workplace: an inclusive systematic review of the empirical literature. Eur J Work Organ Psy 26:492-513. https://doi.org/10. 1080/1359432X.2017.1308924

MacEachern AD, Jindal-Snape D, Jackson S (2011) Child abuse investigation: police officers and secondary traumatic stress. Int J Occup Saf Ergon 17:329-339. https://doi.org/10.1080/10803548. 2011.11076898

Maddox L, Lee D, Barker C (2011) Police empathy and victim PTSD as potential factors in rape case attrition. J Police Crim Psychol 26:112-117. https://doi.org/10.1007/s11896-010-9075-6

Maran DA, Varetto A, Zedda M, Ieraci V (2017) Occupational stress, anxiety and coping strategies in police officers. Occup Med 65:466-473. https://doi.org/10.1093/occmed/kqv060

Marshall EK (2006) Cumulative career traumatic stress (CCTS): a pilot study of traumatic stress in law enforcement. J Police Crim Psychol 21:62-71. https://doi.org/10.1007/BF02849503

McCarty WP, Zhao JS, Garland BE (2007) Occupational stress and burnout between male and female police officers: are there any differences? Policing: An International Journal of Police Strategies \& Management 30:672-691. https://doi.org/10.1108/ 13639510710833938

McCormack N, Cotter C (2013) Managing burnout in the workplace: a guide for information professionals. Woodhead Publishing Limited.

Nolte AGW, Downing C, Temane A, Hastings-Tolsma M (2017) Compassion fatigue in nurses: a metasynthesis. J Clin Nurs 26:43644378. https://doi.org/10.1111/jocn.13766

Oxburgh G, Ost J (2011) The use and efficacy of empathy in police interviews with suspects of sexual offences. J Investig Psychol Offender Profiling 8:178-188. https://doi.org/10.1002/jip.143

Oxburgh G, Ost J, Morris P, Cherryman J (2015) Police officers' perceptions of interviews in cases of sexual offences and murder involving children and adult victims. Police Pract Res 16:36-50. https://doi.org/10.1080/15614263.2013.849595

Parkes R, Graham-Kevan N, Bryce J (2018) You don't see the world through the same eyes anymore: the impact of sexual offending work on police staff. Police Journal: Theory, Practice and Principles 1-23. https://doi.org/10.1177/0032258X18812515

Pehlivan T, Guner P (2018) Compassion fatigue: the known and unknown. J Psychiatr Nurs 9:129-134. https://doi.org/10.14744/ phd.2017.25582

Perez LM, Jones J, Englert DR (2010) Secondary traumatic stress and burnout among law enforcement investigators exposed to disturbing media images. J Police Crim Psychol 25:113-124. https://doi. org/10.1007/s11896-010-9066-7

Peterson JK, Silver RC (2017) Developing an understanding of victims and violent offenders: the impact of fostering empathy. J Interpers Violence 32:399-422. https://doi.org/10.1177/088626051558636

Powell MB, Cassematis P, Benson MS, Smallbone S, Wortley R (2014a) Police officer's perceptions of the challenges involved in internet child exploitation investigation. Policing: An International Journal of Police Strategies and Management 37:543-557. https:// doi.org/10.1108/PIJPSM-08-2013-0080

Powell MB, Cassematis P, Benson MS, Smallbone S, Wortley R (2014b) Police officer's strategies for coping with the stress of investigating internet child exploitation. Traumatology: An International Journal 200:32-42. https://doi.org/10.1037/h0099378

Rose TB (1999) The relationships between world view and empathy: a study of police officers. Bell \& Howell Information and Learning Company. 
Segal EA, Gerdes KE, Lietz CA, Wagaman MA, Geiger JM (2017) Assessing empathy. Columbia University Press

Shamay-Tsoory SG (2011) The neural bases for empathy. Neuroscientist 17:18-24. https://doi.org/10.1177/1073858410379268

Sifris A, Williams B, Kordouli V (2015) Empathy and mental health. Law Institute Journal, Mental Health Special Issue 38-40. https:// doi.org/10.1016/j.ijlp.2018.01.009

Sprang G, Clark JJ, Whitt-Woosley A (2007) Compassion fatigue, compassion satisfaction, and burnout: factors impacting a professional's quality of life. J Loss Trauma 12:259-280. https://doi.org/ 10.1080/15325020701238093

Sprang G, Craig C, Clark J (2011) Secondary traumatic stress and burnout in child welfare workers: a comparative analysis of occupational distress across professional groups. Child Welfare 90:149-168. https://www.cwla.org/child-welfare-journal/

Stamm BH (2010) The concise ProQOL manual ( $2^{\text {nd }}$ ed. $)$. http://www. ProQOL.org

Steed L, Bicknell J (2001) Trauma and the therapist: the experience of therapists working with the perpetrators of sexual abuse. Australas J Disaster Trauma Stud 1:527-540. https://www.massey. ac.nz/ trauma/

Tehrani N (2016) Extraversion, neuroticism and secondary trauma in internet child abuse investigators. Occup Med 66:403-407. https:// doi.org/10.1093/occmed/kqw004

Tomyn AJ, Powell MB, Cassematis P, Smallbone S, Wortley R (2015) Examination of the subjective well-being of Australian internet child exploitation investigators. Aust Psychol 50:203-211. https:// doi.org/10.1111/ap.12119

Virgili M (2015) Mindfulness-based interventions reduce psychological distress in working adults: a meta-analysis of intervention studies. Mindfulness 6:326-337. https://doi.org/10.1007/ s12671-013-0264-0

Wagaman MA, Geiger JM, Shockley C, Segal EA (2015) The role of empathy, burnout, compassion satisfaction, and secondary traumatic stress among social workers. Soc Work 60:201-209. https:// doi.org/10.1093/sw/swv014

Way I, Van Deusen KM, Martin G, Applegate B, Jandle D (2004) Vicarious trauma: a comparison of clinicians who treat survivors of sexual abuse and sexual offenders. J Interpers Violence 19:4971. https://doi.org/10.1177/0886260503259050

Wright R, Powell MB, Ridge D (2006) Child abuse investigation: an in-depth analysis of how police officers perceive and cope with daily work challenges. Policing: An International Journal of Police Strategies \& Management 29:498-512. https://doi.org/10.1108/ 13639510610684728

Yilmaz G, Ustun B (2018) Professional quality of life in nurses: compassion satisfaction and compassion fatigue. J Psychiatr Nurs 9:205-211. https://doi.org/10.14744/phd.2018.86648

Publisher's Note Springer Nature remains neutral with regard to jurisdictional claims in published maps and institutional affiliations. 